thereby asserts that it is false to say that our knowledge is only relative. In that case some of our knowledge must be absolute ; but this upsets the foundation of the whole system. Anyone who upholds such a system as this may be compared to a man seated high up on the branch of a tree which he is engaged in sawing across where it springs from the tree's trunk. The position taken up by such a man would hardly be deemed the expression of an exceptional amount of wisdom.

My time has expired, and I may say no more. The considerations I have put before you this evening, should they commend themselves to your judgment, will, I think, lead you to admit that, if we feel confidence and certainty in any part of any branch of physical science, we thereby implicitly affirm that the human mind can, by consciousness and memory, know more than phenomena-can know some objective reality-can know its own continuous existence--the validity of inference and the certainty of universal and necessary truth as exemplified in the law of contradiction. In other words, the system of the relativity of knowledge is untrue. Thus the dignity of that noble, wonclerful power, the human intellect, is fully established, and the whole of our reason, "from turret to foundation-stone," stands firmly and secure. If I have succeeded in bringing this great truth home to one or two of my hearers who before doubted it, I am abundantly repaid for the task I have undertaken. It only remains for me now to thank you for the kind and patient hearing you have been so good as to accord me.

\section{EXAMINATIONS IN SCIENCE.}

THE Committee of the Privy Council on Education have just announced an important decision with regard to the examinations of the Science and Art Department in science.

The number of candidates presenting themselves for examination in science is already so large-about 190,000 papers in various branches of science were worked at the examination in May last, besides above 14,000 practical examinations-that the machinery of examination and registration is already severely strained. These numbers will in all probability soon be so increased as to render it impossible to make satisfactory arrangements for the examination of the candidates at the local centres, or for the examination of the worked papers under any system of central examination.

At the same time the means recently placed at the disposal of local authorities for providing or aiding instruction seem to render it unnecessary for the Science and Art Department to continue to give direct aid for very elementary instruction in science. Such instruction can now be more effectuaily organized and maintained locally.

Under these circumstances it has been decided that after the May examinations of 1892 the payments of $£ 1$ now made for the second class in the elementary stage of each science subject shall cease. ${ }^{1}$ An elementary paper will continue to be set in each subject, but the results will be recorded simply as pass or fail, the standard for passing being about the same as that now required for a first class, i.e. about 60 per cent. of the marks obtainable.

At the same time, with a view to encourage more advanced instruction, which does not seem to be adequately provided for at present, the payments for the advanced stage and for honours will be considerably increased. The payments on results will then be $\AA^{2}$ for a pass in the elementary stage; $£ 5$ and $£_{2}$ 10s. for a first or second class respectively in the advanced stage; and $£ 8$ and $\downarrow 4$ for a first or second class respectively in honours, in each subject of science, and in each subdivision of

I The payments on the results of the examinations in 1892 will not be affected by this Minute.

$$
\text { NO. I I } 52 \text {, VOL. } 45]
$$

subject 6 , theoretical mechanics, or of subject 8 , sound, heat, and light, with the following exceptions:- The payments for practical chemistry will be $£ 3$ for a pass in the elementary stage, and $£ 6$ and $£ 3$ Ios respectively for a first or second class in the advanced stage; the payments for mathematics will be $£ 2$ for a pass in stage $1, £ 3$ and $£ 2$ respectively for a first or second class in stages 2 and $4, £ 4$ and $£ 3$ for a first or second class respectively in stage $3, £ 5$ and $£ 4$ for a first or second class respectively in stages 5,6 , and 7 , and $£ 8$ and $£ 4$ respectively for a first or second class in honours. The payment for section I (geometrical drawing) of subject $\mathrm{I}$ will remain as at present, Ios.

The payment for attendance in an organized science school will be increased to $£ \mathrm{I}$ in the day school and 10 s. in the night school.

As it is of great importance to prevent large numbers of wholly unqualified candidates being presented at the examinations, the examiners will be instructed to note the papers of all such as would not obtain above twentyfive per cent. of the marks, and a deduction will be made from the grant to each school for each such paper sufficient to cover the cost incidental to its examination.

The committee of a science school in a place in Great Britain with less than 5000 inhabitants which does not receive aid from the local authority, or of any science school in Ireland, will be allowed to continue until further notice on the present system, if they so desire it.

\section{NOTES.}

THE subject of an International Congress of Electricity, to be held at Chicago in connection with the World's Fair, continues to attract much attention in America. A report about the matter has been presented to the Director-General of the Exhibition by Mr. J. Allen Hornsby, secretary of the department of electricity. During a recent visit to Europe, Mr. Hornsby discussed the question with several leading men of science in England and on the Continent, and he was encouraged by them to believe that, if certain conditions were complied with, the success of the Congress would be certain. They all agreed that the Congress should be held under the auspices of the U.S. Government. Invitations, they thought, should be issued by the Government to individual scientific men through the Governments of the countries to which the individuals belong. "This course of action," says Mr. Hornsby, " in the opinion of the authorities whom I consulted, will insure an official character to the proceedings of the scientific Congress, and will virtually pledge the various Governments to a recognition and adoption of the standards created."

Prof. Joseph Wolstenholme, whose name was well known to mathematicians, died on November 18 in his sixty-third year. He graduated at Cambridge as third wrangler in the Mathematical Tripos of 1850 , and became a Fellow first of St. John's College, then of Christ's, where he was for many years a member of the tutorial staff. After vacating his Fellowship by marriage in 1869 , he was appointed the first Professor of Mathematics in the Engineering College at Cooper's Hill-a position from which failing health compelled him to withdraw a year or two ago. With the Rev. Percival Frost, he wrote a treatise on solid geometry, published in 1863 . He also collected many original mathematical problems, devised by himself, in a volume which appeared in 1867 , and again in 1878 .

WE regret to announce the death of Mr. S. F. Downing Principal of the Civil Engineering College, Seebpur, Calcutta, which took place at Coonoor, Madras, on October 16 last, at the comparatively early age of forty-seven. The Englishman of October 24 says :--" The deceased gentleman was educated at Trinity College, Dublin, and was a graduate of Dublin 